\title{
A importância das ações educativas nos museus
}

The importance of educational actions in museums

\section{Heloisa Helena Fernandes Gonçalves da Costa}

Universidade Federal da Bahia - UFBA - Salvador - Bahia - Brasil

\section{Verlaine Fátima Wazenkeski}

\author{
Universidade Federal de Pelotas - UFPEL - Pelotas - Rio Grande do Sul - Brasil
}

Resumo: Destaca-se neste artigo a importância das ações culturais e educativas nas instituições museológicas. O artigo aborda e valoriza esta importante ferramenta para atrair um maior número de visitantes para estas instituições, onde a comunidade em geral, e principalmente, estudantes e professores, possam frequentar estes locais e se apropriarem dos mesmos, encontrando não somente um ambiente de formação do conhecimento, bem como de divertimento, de lazer, independente da faixa etária ou rede escolar aos quais eles pertençam. Assim como a história dos indivíduos na sociedade vem constantemente se modificando, os museus também precisam acompanhar essas mudanças, reformulando a sua interação junto ao público, para que não permaneçam com hábitos arraigados na antiga tradição de guardiões de coisas do passado, onde apenas a observação era permitida e estimulada. O desenvolvimento de ações educativas nos museus surge como essencial ferramenta, não somente na intenção de chamar o público para o museu, mas de construir informação, possibilitando que as pessoas que ali estejam reconheçam e compreendam a história que estes locais trazem consigo. São nas ações educativas que o profissional de museu encontra o momento ideal para trabalhar com os grupos temas atuais da realidade, mesmo da própria comunidade onde está inserida, a partir do conteúdo material e imaterial contado no museu.

Palavras-chave: Ações Educativas. Museus. Comunidade. Educação Patrimonial.

Abstract: It stands out in this article the importance of cultural and educational activities in the museum institutions. The article discusses and values this important tool to attract a greater number of visitors to these institutions, where the community in general, and especially students and teachers, to attend these sites and take ownership of them, not only finding a training environment knowledge as well as fun, leisure, regardless of age or school network to which they belong. Just as the history of individuals in society is constantly changing, the museums also need to keep up with these changes, reformulating their interaction with the public, so that not remain with ingrained habits in the ancient tradition of the last things guardians, where only the observation it was allowed and encouraged. The development of educational activities in museums emerges as an essential tool, not only in an attempt to draw the public to the museum, but to build information, enabling people who are there to recognize and understand the history that these sites bring with them. Are the educational activities that the museum professional is the ideal time to work with the current issues groups of reality, even the community where it operates, from the material and immaterial content counted in the museum.

Keywords: Actions Education. Museums. Community. HeritageEducation. 


\section{Introdução}

Falar da relação intima entre ações culturais e educativas nas instituições museológicas e a formação de público visitante nunca parece ser demasiado. Em que pese a existência de farta publicação de artigos resultantes de pesquisas nessa área, há sempre uma novidade em cada instituição, quer seja em razão do tipo de acervo, quer seja por imaginação criativa das equipes ou ainda por associar essa criatividade com maior quantidade de recursos financeiros, humanos e materiais.

Conforme define o Estatuto dos Museus, os museus são:

\begin{abstract}
"Instituições sem fins lucrativos que conservam, investigam, comunicam, interpretam e expõem para fins de preservação, estudo, pesquisa, educação, contemplação e turismo, conjuntos e coleções de valores históricos, artísticos, científicos, técnicos, ou de qualquer outra natureza cultural, aberta ao público, a serviço da sociedade e de seu desenvolvimento". (IBRAM, 2009)
\end{abstract}

Sabe-se que a ideia de museu se originou desde tempos muito remotos, em que o homem adquiriu o hábito de colecionar coisas, objetos que lhe conferissem os mais diversos significados e que se tornavam símbolos de sua própria história. No século XVII, os museus começam a se moldar, até chegar como 0 conhecemos nos dias atuais. Várias mudanças acontecem nestas instituições, aonde vai surgindo a exigência de profissionais capacitados nas mais diversas áreas: museólogos, historiadores, pedagogos, conservadores-restauradores e arqueólogos.

Os museus deixam de ser espaços de fruição estética apenas, ou de transmissores de curiosidades e exotismo através de objetos resultantes de conquistas bélicas, e passam a ter um importante espaço de interpretação de culturas e de educação dos cidadãos, fortalecendo a cidadania e o respeito às diferenças culturais.

Segundo o Caderno de Diretrizes Museológicas (MINC, 2006), procedimentos que promovem a educação no museu, tendo o acervo como o centro das atividades, podem estar voltados para a transmissão de conhecimento dogmático, resultando em doutrinação e domesticação, ou para a participação, reflexão crítica e transformação da realidade social. Neste caso, as atividades devem ser entendidas como uma ação cultural, que consiste no processo de mediação, permitindo ao homem apreender, em um sentido amplo, o bem cultural, com vistas ao desenvolvimento de uma consciência crítica e abrangente da realidade que o cerca. Seus resultados devem assegurar a ampliação das possibilidades de expressão dos indivíduos e grupos nas diferentes esferas da vida social. Concebida dessa maneira, a ação cultural e educativa nos museus promove sempre amplo benefício para a sociedade, atendendo em última instância, ao papel social inerente às instituições museológicas.

De acordo com Denise Grinspum (2001, p.2), desde que o museu tornou-se público, no século XVIII, a função social deste tem sido motivo para justificar sua existência. Atualmente, sob a égide das novas tendências museológicas, o compromisso sociopolítico dos museus é, antes de tudo, educacional, e sua nova definição aponta para "instituições de serviço público e educação, um termo que inclui exploração, estudo, observação, pensamento crítico, contemplação e diálogo".

\section{Ações Educativas}

O documento de Diretrizes para elaboração do Programa Educativo e Cultural dos Museus da Superintendência de Museus e Artes Visuais de Minas Gerais define ações educativas como:

Elementos fundamentais no processo de comunicação que, juntamente com a pre $\neg$ servação e a investigação, formam o pilar de sustentação de todo museu, qualquer que seja sua tipologia. Entendidas como formas de mediação entre o sujeito e o bem cultural, as ações educativas facilitam sua apreensão pelo público, gerando respeito e valorização pelo patrimônio cultural. (CADERNO de Diretrizes Museológicas, 2006)

A sociedade muda diariamente, e assim os indivíduos adquirem novas perspectivas de vida e 
com elas o desejo de aprender, combinando igualmente seu conhecimento cultural com 0 desenvolvimento de uma cidadania responsável. Assim acontece também com os museus que precisam estar sempre se renovando, se redescobrindo para que não permaneçam com hábitos arraigados na antiga tradição de "guardiões de coisas do passado" dando a impressão de serem espaços onde só existem coisas velhas têm lugar, locais onde se entra com cuidado, falando baixo para não assustar os "fantasmas" que talvez convivam com salas tristes e sombrias. Hoje percebe-se que um museu renovado, pleno de atividades culturais e educativas exerce grande atração sobre os mais variados públicos, enfatiza a ideia de que todos podem e devem se apropriar daquele local de encantamento, cultura e lazer.

Santos afirma que:

Museu para a maioria dos professores e alunos, ainda permanece como "um local onde se guarda coisas antigas". Do mesmo modo, o patrimônio cultural é compreendido como algo que se esgota no passado, cabendo às pessoas, sujeitos sociais, contemplá-lo, de maneira passiva, sem nenhuma relação com a vida, no presente. Cultura, patrimônio e tradição são produtos dissociados do cotidiano do professor e da vida dos seus alunos. (SANTOS, 2002, p.311)

Nesse sentido, o desenvolvimento de ações educativas nos museus surge como vital ferramenta com o objetivo de ir muito além do simples chamamento de público para o recinto, mas de construção de conhecimento, entretenimento, encantamento, possibilitando reconhecer e mudar atitudes, bem como modificar o modo de ver as coisas, os objetos, as pessoas e as relações entre nós mesmos.

Este assunto deve ser tratado e trabalhado com os educadores, para que eles próprios entendam o que é um museu e, assim, possam refletir e entender o que é cultura, patrimônio e tradição, e, ao levarem seus alunos a uma visita ao museu, estes momentos passados dentro da instituição sejam realmente aproveitados em todos os sentidos.
Toda vez que as pessoas se reúnem para construir e dividir novos conhecimentos, que investigam pra conhecer melhor, que procuram entender e transformar a realidade que nos cerca, estamos falando de uma ação educativa. Quando fazemos tudo isso levando em conta alguma coisa que tenha relação com nosso patrimônio cultural, então estamos falando de Educação Patrimonial.

O Instituto do Patrimônio Histórico e Artístico Nacional - IPHAN atualmente concebe educação patrimonial como todos os processos educativos que primem pela construção coletiva do conhecimento, pela dialogicidade entre os agentes sociais e pela participação efetiva das comunidades detentoras das referências culturais onde convivem noções de patrimônio cultural diversas.

Santos escreve que:

Assim como a educação, o patrimônio cultural é o referencial básico para o desenvolvimento das ações educativas. Os processos museais gerados ao longo dos anos contribuíram de modo efetivo para a ampliação do seu conceito, à medida que, para sua aplicação, o patrimônio cultural é compreendido como relação do homem com o meio, ou seja, o real na sua totalidade: material, imaterial, natural e cultural em suas dimensões de tempo e espaço (SANTOS, 2002, p.312).

Angélica K. Schwanz (2004, p.12) comenta que a metodologia da educação patrimonial começa a ser difundida no Brasil em meados dos anos 80 do séc. XX, por ocasião dos primeiros debates conceituais e práticas sobre este assunto, mais especificamente, durante o $1^{\circ}$ Seminário sobre o "Uso Educativo de Museus e Monumentos", que aconteceu em julho de 1983, no Museu Imperial, em Petrópolis, RJ, sob a coordenação da museóloga Maria de Lourdes Parreiras Horta. Este método foi desenvolvido para propiciar a criação de programas didáticos nos museus e o objetivo principal foi 0 estudo no próprio museu. A partir da experiência promovida pelo Museu Imperial, em Petrópolis, que contou com a parceria do Heritagelnstitute da Inglaterra, a ideia de Educação Patrimonial se estabeleceu no Brasil. Após essa marcante experiência, da qual a grande maioria de museólogos 
gestores de museus nacionais participou, é que o conceito de Educação Patrimonial foi se consolidando, até que a surgiu uma publicação especifica sobre o tema, que hoje é um guia para todos que se interessam nesse tipo de método educativo com uso do patrimônio cultural.

No mesmo trabalho de Schwanz há uma citação de Magaly Cabral que expõe o que considera sejam os objetivos da Educação Patrimonial:

- Buscar trazer para a sua ação o que o bem cultural pode oferecer para uma discussão a respeito da relação do indivíduo com a realidade;

- Buscar a identificação de significados e sentidos, num contexto que é diferente para o usuário, já que percepções e identificações significadas e sentidos variam de acordo com as experiências passadas de cada um, vivenciadas dentro de seu contexto histórico - social;

- Tratar o bem cultural propondo hipótese sobre o que significa para o indivíduo, buscando um movimento de recriação e reinterpretação das informações, conceitos, e sentidos nele contidos (CABRAL, 2002, apud Schwanz 2004, p. 13).

Nascimento cita um ponto de referência para também nos fazer refletir que:

Trabalho de construção de uma prática educativa em um museu envolve o universo cultural. Falar em cultura é sempre um desafio teórico, pois ela se compõe de ideias, concepções, significados sempre reelaborados, ao longo do tempo e do espaço. Os significados e concepções atribuídos pelos membros do grupo e por eles partilhados se expressam concretamente, seja através das práticas sociais, do discurso, da fala, das manifestações artísticas ou, ainda, da criação de objetos. (NASCIMENTO, 2005, p.231)

De acordo com obra "Museu e a Vida" os autores explanam que o "Museu redimensiona-se". "Antes passivo, ordena-se ativo", não mais o objeto em si, mas o resumo histórico e o contexto são de suma importância no que se refere às ações educativas, mesmo que o museu reajuste conforme sua necessidade, sua função didática. No museu se combinam o estético e o pedagógico, conceitua-se no contexto histórico e por área geográfica. Cada museu responde a algum aspecto do saber humano. Concentra-se, especializa-se e torna-se antagonicamente mais amplo. O método visual é a sua linguagem'.

Um museu e seus artefatos são instrumentos privilegiados para a educação patrimonial. Magaly Cabral (2002) diz que se o patrimônio é terreno em construção, fruto de eleição, campo de combate, espaço de relações humanas, é também "meio de comunicação e campo de educação", podendo e devendo ser objeto de ações educativas que contribuam para a mudança social por "ensinar a pensar criticamente, fornecendo os instrumentos básicos para o exercício da cidadania".

Sobre ações sistemáticas de educação patrimonial, nos cita Maria de Lourdes Horta que:

A partir da experiência e do contato direto com as evidências e manifestações da cultura, em todos os seus múltiplos aspectos, sentidos e significados, o trabalho da Educação Patrimonial busca levar as crianças e adultos a um processo ativo de conhecimento, apropriação e valorização de sua herança cultural, capacitando-os para um melhor usufruto destes bens, e propiciando a geração e a produção de novos conhecimentos, num processo contínuo de criação cultural. (HORTA, 2003, p.6)

É importante que o museu atraia o público para junto de si, para que pessoas que não têm o hábito de visitá-lo passem a fazê-lo. Neste momento, a ação educativa deve ser apresentada de uma forma descontraída, interessante para que o aluno que ali estiver, saiba que é um local de cultura, mas também de grande ludicidade. A educação vista e vivida através do patrimônio cultural traz consigo uma das mais agradáveis experiências para as crianças e adultos.

Neste sentido, Magaly Cabral e Aparecida Rangel ressaltam um elemento essencial:

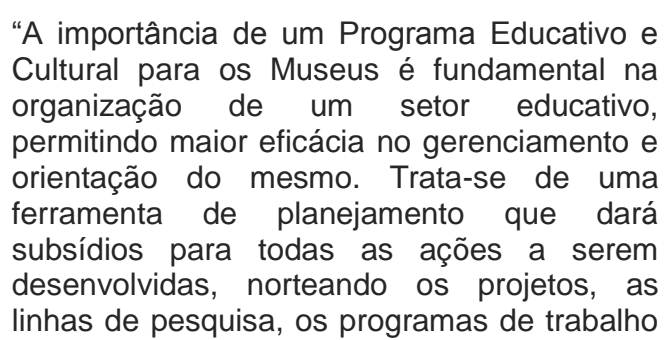


e as atividades. Pelo alcance do mesmo é importante que, na sua elaboração, haja a participação de todos os profissionais envolvidos com o setor, independentemente do seu status profissional. O Programa Educativo e Cultural deve ser parte integrante do Plano Museológico da instituição e estar em sintonia com este." (IBRAM, 2009)

Para que haja um bom funcionamento com as ações educativas nos museus é recomendado que seus servidores sejam qualificados e engajados com participação ativa, proporcionando assim novos conhecimentos culturais e artísticos, de modo que a instituição possa fazer com que as crianças e o público em geral sintam-se bem acolhidos. Como explana Marília X. Cury (2004):

“... pode-se dizer que a comunicação museológica só se efetiva quando o discurso do museu é incorporado pelo visitante e integrado ao seu cotidiano, agora como um novo discurso. (...) a concepção de comunicação como transmissão de conhecimento e/ou informação está superada, pois não dá conta das construções simbólicas. Tampouco considera o público como participante ativo, o que de fato ele é".

Conforme coloca Heloisa Helena Costa (2013, pag.03) em seu artigo: "Museu, Educação e Comunicação", nos últimos tempos o Brasil vem implantado políticas públicas de inclusão social que tem sido expressões concretas em áreas afins do governo, especialmente em educação e cultura. Na área da cultura há um esforço para reorganizar e incentivar um novo olhar sobre o patrimônio como estratégia privilegiada de substituição do modelo tradicional de organização que priorizava o cuidado com os monumentos, edifícios e museus, apena no viés das técnicas de conservação.

Entretanto, há que se pensar no que o Ministério da Educação vem propondo como política pública. O modelo atual que está sendo adotado em nosso país é o de uma pedagogia coletiva, ou seja, uma única forma de ensino para todos, como se todas as pessoas pensassem ou agissem da mesma forma.

Talvez já estejamos todos em atraso para ir buscar no pensamento de Anísio Teixeira, grande educador e fundador do INEP - Instituto Nacional de
Estudos Pedagógicos, órgão que detém a autoridade de pesquisar, orientar e avaliar as práticas pedagógicas de universidades e escolas brasileiras, a melhor forma de educar crianças, jovens e adultos:

[...] ao invés de sistemas paralelos e duplicados de escolas, auxiliaria o Governo Federal, as instituições básicas - bibliotecas e museus - que iriam servir, em cada estado, de focos permanentes para a vitalidade e a riqueza das próprias escolas. Precisamos sair das pequeninas e estreitas reivindicações unificantes de currículos e programas e sentir que a unidade e a vitalidade das culturas se promovem pela difusão, fertilização mútua de suas variedades, entre si [...], daí serem os museus e bibliotecas as instituições básicas da educação. Não seria absurdo dizer que, em verdade, antecedem à escola. Pois esta só pode realmente educar se tiver a nação um sistema de bibliotecas e museus". (TEIXEIRA 1956 apud ALMEIDA E FREITAS, 2006, p.195)

Com um novo pensamento, cria-se um modelo pedagógico inovador, que preconiza um processo de educação utilizando a metodologia ativa de ensinoaprendizado, onde os desafios a serem vencidos pelos estudantes lhes possibilitará um lugar de sujeitos da construção dos conhecimentos, colocando assim o professor como um facilitador e orientador, através de uma dinâmica onde o diálogo é o que prevalece.

Para isso, deve-se ter a perspectiva e o equilíbrio entre a excelente técnica e a relevância social, configurando como princípios norteadores do movimento de mudança. Desta forma podemos constatar o quanto está sendo importante para as instituições museológicas este entrosamento entre elas e as escolas com a participação ativa dos professores e seus alunos.

Pode-se até prever 0 processo ensino/aprendizagem baseado em resolução de problemas em pequenos grupos, nos quais os professores formadores trabalhem como tutores, ocorrendo o ensino em ambientes diversificados centros de interpretação, sítios históricos, laboratórios, de simulação, ambiente patrimoniais - e com atividades estruturadas partir das necessidades.

Moema Nascimento Queiroz também nos coloca de forma clara que é através da educação 
patrimonial que acontece o processo de ensino e aprendizagem podendo ser dinamizado e ampliado, muito além do ambiente escolar onde uma comunidade inteira pode estar envolvida. Pode tornarse um instrumento a mais no processo de educação que colabore com o despertar de uma consciência crítica e de responsabilidade para com a preservação do patrimônio - em toda sua expressão - e a percepção da relação entre esse com sua identidade pessoal e cultural. Um exemplo dessa prática é a experiência bem sucedida da Quarta Colônia de Imigração Italiana, nas proximidades de Santa Maria, no Rio Grande do Sul, onde atuaram pontualmente Hugues de Varine, Maria de Lourdes Horta e Evelyne Grinsberg.

Sendo assim, ao incorporarmos este instrumento de ação, iremos ao encontro do pensamento de Paulo Freire, buscando uma "alfabetização cultural" que capacite o educando a compreender sua identidade cultural e a se reconhecer, de forma consciente, em seus valores próprios, em sua memória pessoal e coletiva. Ainda segundo nosso pensador, "a criticidade $e$ as finalidades que se acham nas relações entre os seres humanos e o mundo implicam em que estas relações se dão com um espaço que não é apenas físico, mas histórico e cultural". (FREIRE, 2003, p.81)

\section{História do Museu Municipal Divino Alziro Beckel}

O prédio onde hoje se encontra o Museu Municipal Divino Alziro Beckel foi construído no ano de 1903 e concluído em 1904, com todo o conforto possível para a época. Em estilo eclético - colonial, com 468,96 metros quadrados, de forma regular em "U" fechado por pilares e grades em ferro, com todos os compartimentos voltados para um longo e espaçoso este corredor e aberto para o pátio interno.

Este imóvel foi construído para ser a moradia do General Zeca Netto e sede da Fazenda da Chácara. Com a morte do General houve um período de abandono da residência, ficando esta em estado muito precário.
Figura 01: Prédio Forte Zeca Netto, onde localiza-se o Museu Municipal Divino Alziro Beckel

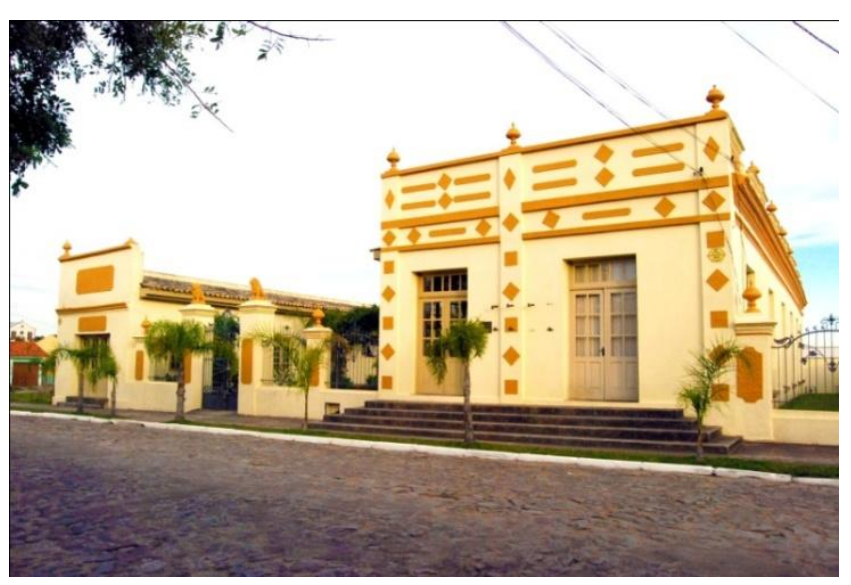

Fonte: Museu - SMCT (2015)

Por seu inigualável valor histórico, o espaço foi adquirido pela Prefeitura Municipal de Camaquã em 1991, e tombado como Patrimônio Público Cultural do Estado do Rio Grande do Sul, em 09 de julho de 1992. Em 1996, o Forte Zeca Netto foi entregue à comunidade.

Encontram-se atualmente neste local, a Secretaria Municipal de Cultura e Turismo, o Museu Municipal Divino Alziro Beckel, a Biblioteca Pública Oswaldo Lessa da Rosa e a Biblioteca "Rio Grande do Sul - Pedaço do Mundo", parte do acervo particular do escritor Barbosa Lessa. Este museu foi criado em 03 de abril de 1979.

Com a morte do senhor Divino Alziro Beckel jornalista, pesquisador e historiador (1913-1986), membro-fundador da ACIC (Associação Comercial e Industrial de Camaquã) e fundador do Jornal "O Camaquâ"- o acervo municipal ganhou a denominação de Museu Municipal Divino Alziro Beckel, em 18 de maio de 1987, em homenagem ao mesmo.

Este museu começou a partir de um acervo particular pertencente ao senhor Divino, que foi o primeiro funcionário e diretor da instituição, o qual por vários anos reuniu e catalogou objetos, documentos, fotos, armas, enfim todos os objetos que se encontram neste local. 
Figura 02 - Sala de exposição do Museu Municipal Divino Alziro Beckel.

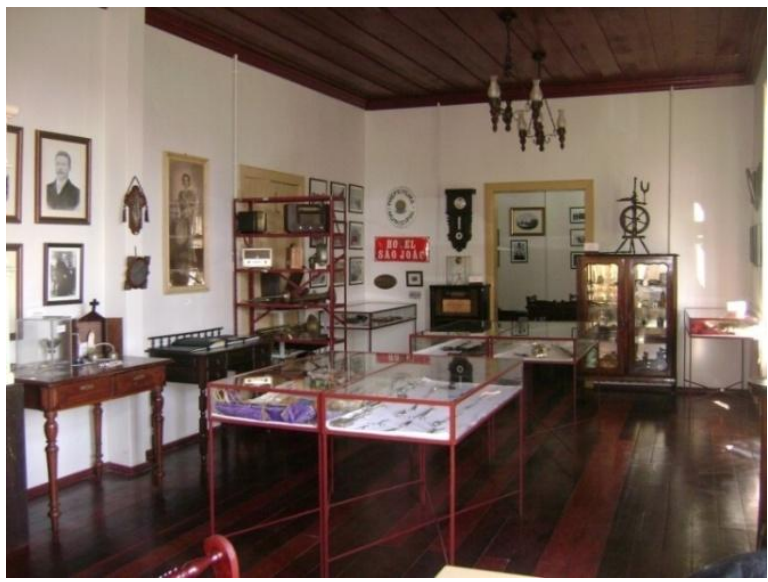

Fonte: Museu - SMCT (2015)

Atualmente o museu possui um grande acervo de objetos, que vai desde moedas, armas, máquinas fotográficas e de costura, livros, fotos, quadros, utensílios de cozinha, relógios, instrumentos musicais, indumentária masculina e feminina, documentos de época e muitos outros objetos, totalizando aproximadamente 1.800 peças. Este prédio foi tombado pelo Patrimônio Histórico do Município em 09 de julho de 1992.

\section{Exemplo de Ação Educativa}

O Instituto Brasileiro de Museus (IBRAM) promove anualmente, a Semana Nacional de Museus, em comemoração ao Dia Internacional dos Museus (18 de maio), onde estas instituições, de todo - Brasil, são desafiadas e estimuladas a proporem ações educativas junto a sua comunidade. $O$ tema gerador é proposto, mas cada museu, dentro da sua realidade, propõe ações nos mais diferentes segmentos. Em sua 13르 edição no ano de 2015 houve 1.378 instituições culturais realizando mais de 4.500 atividades. Este ano o tema foi "Museus para uma sociedade sustentável".

Como exemplo de uma dessas ações trabalhadas in loco, podemos citar o Museu Municipal Divino Alziro Beckel, no município de Camaquã/RS. O tema da ação, sobre sustentabilidade, teve o enfoque na preservação da água. A equipe do museu iniciou a ação dirigindo-se até algumas escolas, fazendo o convite para que os alunos e professores das séries iniciais do Ensino Fundamental, dentro deste tema, pudessem fazer ações relativas ao mesmo, antes ou depois da visita até o museu, que foram organizadas da seguinte forma:

- Quando as crianças chegavam ao museu eram recebidas por uma museóloga e um historiador.

- Exibição da animação: "Um plano para salvar o planeta", da Turma da Mônica, que, de uma maneira bem simples e prática, estimula a fazer reciclagem e debater sobre a importância do cuidado com a água e os demais recursos naturais.

- Exposição de fotos sobre as águas, ruas, praças, mar e rios, mostrando os limpos e os sujos.

- Visitação do poço que faz parte da casa onde o museu está inserido, onde é revista a história do uso de poços nas residências, o uso da água desde os tempos antigos, a restrição do uso e a importância do avanço no tratamento e distribuição da água na sociedade.

- Seguimento na visita com exploração do chafariz da casa e conversa sobre a utilização daquela água - relação desperdício x reciclagem.

- Entrega de instrumento "questionário" com perguntas sobre a importância da água em nossas vidas, para ser trabalhado em aula; os questionários retornaram para o Museu, a fim de registro da ação.

\section{Figura 03: Visita da EMEF Ana Tomázia} Ribeiro

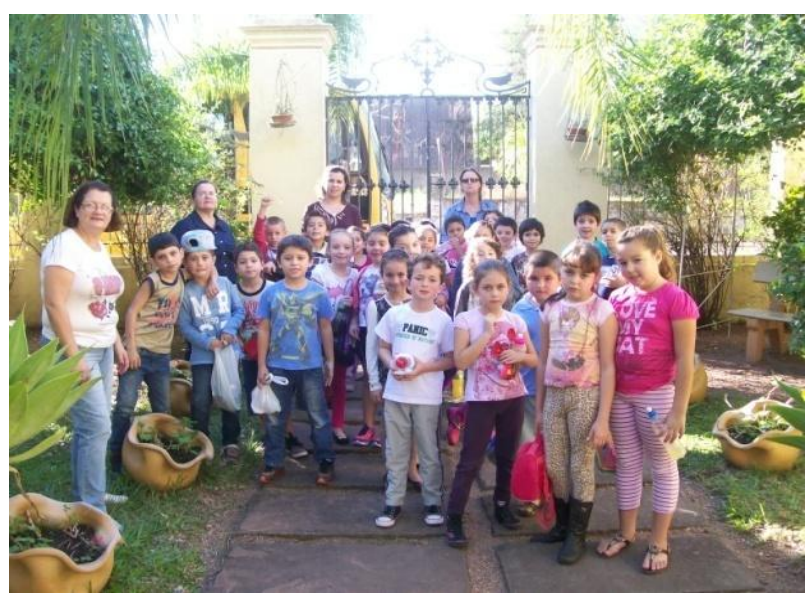

Fonte: Museu - SMCT (2015) 
Figura 04: Visita da EMEF Ana Tomázia

Ribeiro Escolares participando das ações educativas

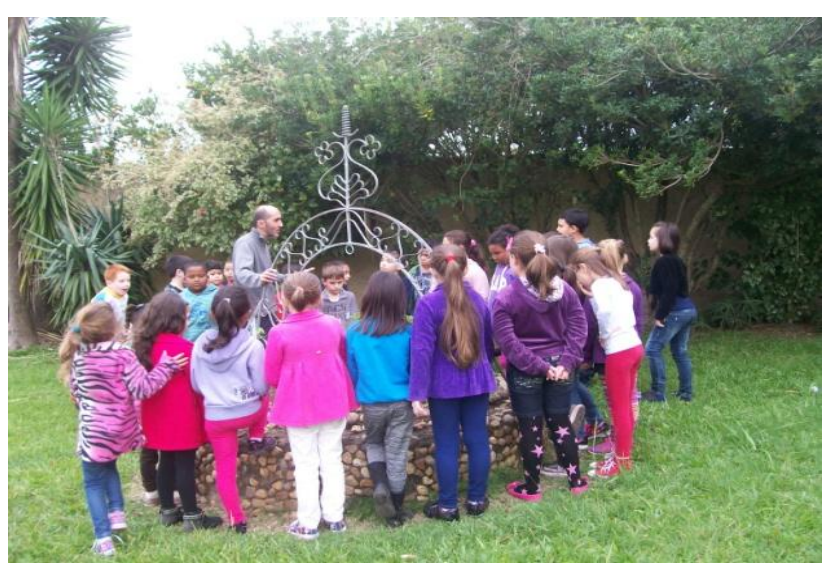

Fonte: Museu - SMCT (2015)

Figura 05: Visita do Colégio Contemporâneo com a participação dos escolares nas ações educativas

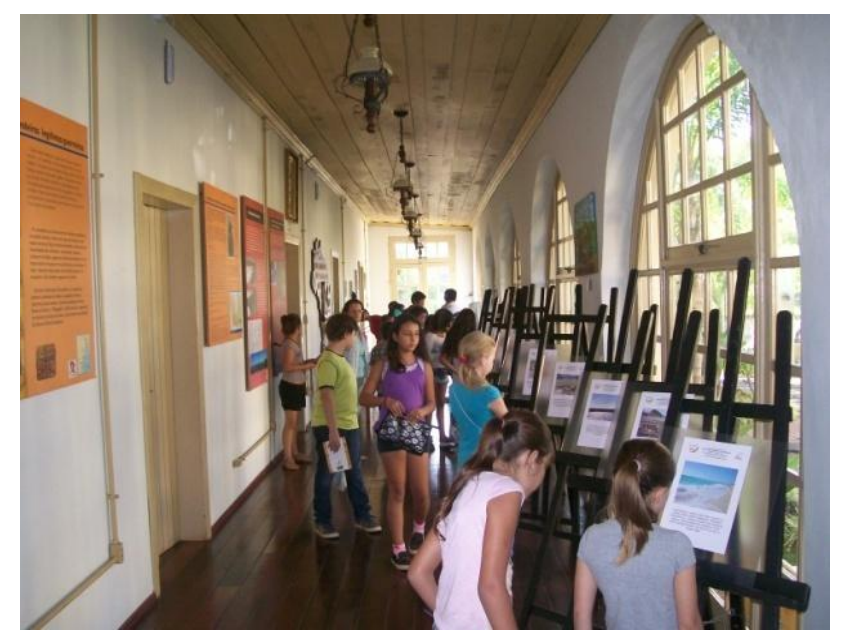

Fonte: Museu - SMCT (2015)
Figura 06: Visita do Colégio Contemporâneo com a participação dos escolares nas ações educativas

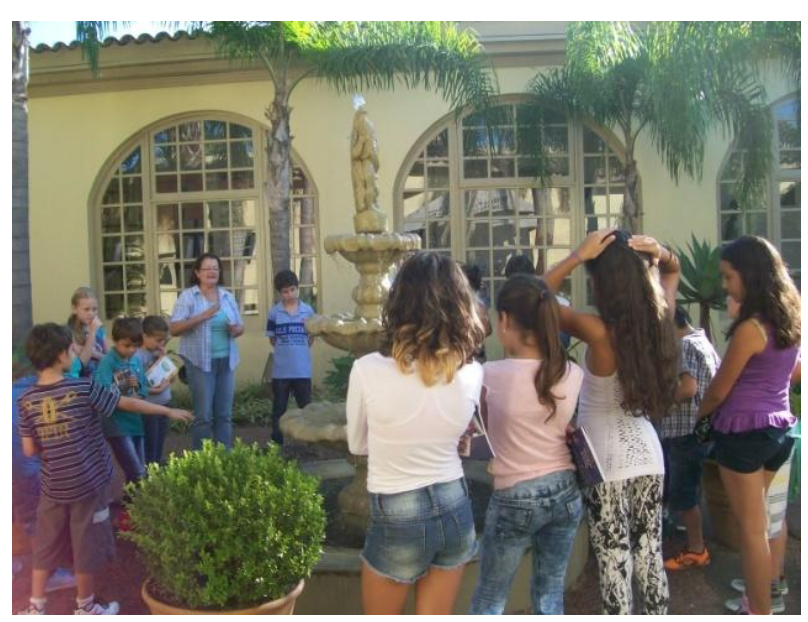

Fonte: Museu - SMCT (2015)

A prática pedagógica aqui descrita é referente à Semana Nacional de Museus, em comemoração ao Dia Internacional dos Museus (18 de maio), tal como foi explicitado anteriormente.

Esta ação foi realizada entre os dias 18 e 22 de maio, recebendo mais de 200 crianças com seus professores, onde as visitas foram conduzidas de forma ativa, debatida, com questionamentos e reflexões junto a cada público participante. Foi elaborada para turmas do $1^{\circ}$ ao $6^{\circ}$ ano do ensino fundamental da rede pública e particular e foi dividida em duas etapas: na primeira, o historiador e a museóloga foram às escolas levar o projetos com as explicações sobre como seriam as ações educativas para os professores; na segunda etapa, foram as escolas que visitaram o museu e participaram de todas as ações oferecidas.

Neste período foram atendidas duas escolas, uma municipal e a outra particular, com a participação de 201 crianças. A escola municipal Ana Tomázia Ribeiro teve uma participação muito significativa, pois trouxe todos seus alunos do $1^{0}$ ao $4^{\circ}$ anos, já a Colégio Contemporâneo participou com 29 alunos do $3^{\circ}$ ano.

Os resultados foram muito positivos com a participação destas duas escolas, sendo que, para este período específico, não houve possibilidade de participação de mais escolas. $O$ museu recebe 
frequentemente várias escolas, mas quando acontece um evento como o que foi descrito acima a procura das escolas se torna muito maior.

\section{Considerações finais}

Os museus devem ser locais sem restrição de público, onde todos sejam bem vindos a visitá-los, a conhecer e se apropriar de todo o conhecimento que os mesmos têm para oferecer. A visitação pode e deve ser um momento de prazer, aventura e aprendizado.

Quando um grupo de estudantes visita uma instituição museológica e é proposta uma ação educativa, a ideia principal não é "ensinar", mas fazer com que as informações sejam passadas de forma simples, lúdica, que cada aluno aprenda se divertindo. A mesma coisa deve acontecer com os professores: antes da visita à instituição, viabilizar a relação das atividades propostas com a escola, tornando o museu instrumento de troca dialógica de conhecimento, de reflexão crítica da história e ação prática, de forma que, aluno e professor construam, individualmente e em grupo, sua relação com aquilo que está dialogando, que temas são de interesse para um melhor aprendizado - adquirindo assim uma maior comunicação entre visitantes e a instituição.

Acredita-se que seja de suma importância a ampliação das atividades ligadas às áreas educacionais dentro dos projetos dosmuseu, já que ao longo do trabalho nota-se a falta de políticas internas com regimentos específicos que possam dar a sustentação para as ações educativas, tendo estas normas e diretrizes, as linhas e os conceitos a serem seguidos e explorados nos projetos aplicados.

Portanto, se faz necessário organizar projetos que viabilizem novas ações e pesquisas dentro dos museus, uma das alternativas pode ser firmar parcerias com outras instituições ou órgãos, como já acontece com o IBRAM (Instituto Brasileiro de Museus) através da participação em editais, uma vez que estes vêm a contribuir de maneira qualitativa para o desencadeamento de novas ações e melhorias dentro destas instituições. Também é de suma importância que a equipe qualificada que vai receber este público esteja sempre repensando suas práticas educativas e assim construindo novas possibilidades, para que haja uma melhor atuação junto aos participantes destas ações educativas nos museus.

\section{Referências}

ALMEIDA E FREITAS. Anísio Teixeira na direção do Inep: Programa para a Reconstrução da Nação Brasileira (1952-1964). Marta Maria de Araújo, Iria Brzezinski (Org.). 2006 Disponível em: http://www.publicacoes.inep.gov.br/portal/download/4 24 Acesso em: 02 de março de 2016.

BARBOSA, Neilia Marcelina; OLIVEIRA, Anna Luiza Barcellos de; TICLE, Maria Letícia Silva. Ação Educativa em Museus: Caderno 04. Belo Horizonte: Secretaria de Estado de Cultura/ Superintendência de Museus e Artes Visuais de Minas Gerais, 2010.

CABRAL, Magaly. Comunicação, educação e patrimônio cultural. Texto apresentado no Fórum Estadual de Museus do RS. Inédito. Rio Grande, 2002.

CABRAL Magaly e RANGEL Aparecida; este texto faz parte do Caderno Temático Comunicaçãoe Educação em Museu, a ser publicado pelo IBRAM. REFERÊNCIAS Adotaram aqui as denominações constantes na Portaria Normativa no 1, de 5 de julho de 2006, publicada no DOU de 11/07/2006.

CADERNO de Diretrizes Museológicas 1. Brasília: Ministério da Cultura / Instituto do Patrimônio Histórico e Artístico Nacional / Departamento de Museus e Centros Culturais, Belo Horizonte: Secretaria de Estado da Cultura/ Superintendência de Museus, $2^{\circ}$ Edição, 2006

COSTA, Heloisa H. F. G. da Museus, Educação e Comunicação. Boletim Informativo do Museu de Arqueologia e Etnologia. Disponível em: <http://www.mae.ufba.br/wpcontent/uploads/2013/09/boletim005.pdf>Acesso em: 26/06/2015.

CURY, Marília Xavier. Os usos que o público faz do museu: a (re) significação da cultura material e do museu. MUSAS - Revista Brasileira de Museus e Museologia. Vol. 1, nำ 1, IPHAN - RJ, 2004.

FREIRE, Paulo. Ação Cultural para a Liberdade e outros escritos. São Paulo: Paz eTerra, 10a ed., 2003, p.81.

GIRAUDY, Danièle; BOUILHET, Henri. O museu e a vida. Rio de Janeiro: FNPM, Porto Alegre: Instituto Estadual do Livro. Belo Horizonte: Universidade Estadual de Minas Gerais, 1990. 
GRINSPUM, Denise; Secretaria de Estado de Cultura de Minas Gerais Superintendência de Museus e Artes Visuais; Coleção Falando de Ações Educativas, № 4; Belo Horizonte / 04/ 2011.

HORTA, Maria de Lourdes Parreiras; GRUNBERG, Evelina; MONTEIRO, Queiroz Adriane. Guia Básico de Educação Patrimonial. Museu Imperial, IPHAN, Ministério da Cultura.

IBRAM - Instituto Brasileiro de Museus. Disponível em:

$<$ http://www.museus.gov.br/acessoainformacao/oibram/> Acesso em: 10/06/2015.

IPHAN. Educação Patrimonial - Programa Mais Educação. Disponível em: $<$ http://portal.iphan.gov.br/uploads/publicacao/EduPat EducPatrimonialProgramaMaisEducacao_fas__m.pd $\bar{f}>$ Acesso em: 05/06/2015.

NASCIMENTO, Silvania Sousa do. O desafio de construção de uma nova prática educativa para os museus. In: FIGUEIREDO, Betânia G.; VIDAL, Diana G. (orgs.) Museus: dos gabinetes de curiosidades à museologia moderna. Belo Horizonte: Argvmentvm, 2005, p. 221-239.

QUEIROZ Nascimento Moema - A Educação Patrimonial como Instrumento de Cidadania. Disponível em: $<$ http://www.revistamuseu.com.br/artigos/art_.asp?id= 3562> Acesso em: 26/06/2015.

SANTOS, Maria Célia Teixeira Moura. Museus e Educação: conceitos e métodos. In: Cienkt, Porto Alegre, n. 31, jan/jun, 2002, p. 311,312.

SCHWANZ, K Angélica, Educação Patrimonial. A pedagogia política do esquecimento, Monografia apresentada ao curso de especialização em Memória Identidade e Cultura Material como requisito parcial para a obtenção do grau de especialista, Pelotas, dezembro 2004. 